\title{
Macroergonomic analysis of two different work organizations in a same sector of a luminary manufacturer
}

\author{
Rosimeire Sedrez Bitencourt ${ }^{\mathrm{a}, *}$ and Lia Buarque de Macedo Guimarães ${ }^{\mathrm{a}}$ \\ ${ }^{a}$ Graduate Program in Industrial Engineering, Federal University of Rio Grande do Sul, Av. Osvaldo Aranha 99 \\ 5 andar, Porto Alegre, RS, Brazil
}

\begin{abstract}
This article presents the analysis of the effect of two different types of work organization (the traditional and a new mechanized, more segmented one) in the packing sector of a luminary manufacturing company in Curitiba, Brazil. A macroergonomic analysis was conducted to evaluate the workers satisfaction with the job; the possible associated postural risk, the level of body pain/discomfort and to compare the two models (traditional and mechanized). The mechanized model showed to involve higher postural risk, to generate more pain and less satisfaction, even in relation to the temperature, illumination, uniform and salary, which are the same for the two groups. Excluding job rotation that was well evaluated and should be adopted for all workers, the new model proved to be worse than the traditional although it also needs improvements.
\end{abstract}

Keywords: participative ergonomics, macroergonomics, packing, luminary

\section{Introduction}

Work segmentation is a common practice in most industries following the traditional Taylor/Ford production model introduced in the beginning of the XX Century, in the Ford car manufacturing plant. Henry Ford's idea was to make the work as simple as possible so the non-skilled workforce could handle the task with a minimum (or non at all) training. As Ford used to say, production should be done by hands and arms while the supervisors have the brain of the system. Although the line production system attended the needs of production, it was far from attending the worker's needs. The segmented work made task repetitive, monotonous, physically and mentally harmful $[4,8,14,10]$, leaving no room for people's growth. The high rates of absenteeism and turnover were two of the outcomes of the "highly productive" Ford system. However, because the system allows for nonskilled, therefore not expensive workforce, the system is still in use in most industries worldwide, mainly in Developing countries. The low wages generally pays for the costs of replacing the workforce, in industries where the quality of the production is not the focus.

This type of work organization was widely studied in the meat packing industry $[5,9,2,23,29,24$, $25,18,27,28]$. Few studies examined packing in supermarket [7] and in the tobacco industry [15]. All studies found that the repetitive character of the job leads to workers' dissatisfaction with the work, high levels of pain/discomfort and high risk of workrelated musculoskeletal disorders (WMSD).

This article presents a case of task segmentation increase in the packaging sector of a luminary manufacturer in the metropolitan region of Curitiba, Brazil. Traditionally, the workers' task was to do the whole packing of a luminary. Due to a managerial decision, a packing machine substituted the manual packing and three workers got involved in the task, one to feed the machine, another to get the pack from the machine and another to put the pack on the pallet. For the managerial staff, mechanization would be an improvement for both workers (who will have less

\footnotetext{
* Corresponding author. E-mail:rosisb@ig.com.br tel: +55 51 3308-3948
} 
manual work) and production (since production will be faster). Because only one machine was introduced, the other workers kept working under the "traditional" model. After eight months of using the new system, the managers contracted an ergonomic analysis to prove the benefits of the new model and confirm the need for more machines acquisition in order to change the whole sector.

The following sections present the macroergonomic analysis performed to evaluate the two models operating in the same sector at the same time, and the obtained results.

\section{Method}

Ergonomic analysis was done with the participatory method Macroergonomic Work Analysis (MA) [20] which is composed by 6 stages: 0) project launching; 1) appraisal for problem identification, 2) diagnosis, for problems evaluation; 3) proposal of solutions, 4) implementation and validation of solutions, 5) conclusion and final report with the details of the intervention. MA assumes the involvement of all actors in the process, in the survey and in the discussion of results, as well as in proposals for solutions, therefore there are gates (in scheduled meetings) between each stage in order to exchange information and engage workers and managerial staff in the intervention process.

The study followed stages 0 to 2 to evaluate and compare the two models considering: 1) the workers satisfaction with and their perception of the work, 2) the level of body pain/discomfort, and 3) the possible associated postural risk.

\subsection{Implementation of the MA method}

Stage 0) Project launching: this stage was accomplished in a meeting when the method and objectives of the study were discussed. Two safety technicians and the manager of the Packing sector gave information about the company, the production system and the manufactured products.

Stage 1) Appraisal: in MA, the appraisal is done with the direct and indirect participation of the workers. Evaluation with the indirect workers 'participation is done by the ergonomists based on nonsystematic observations, information from the $\mathrm{Hu}-$ man Resources, Health and Safety as well as the Production Departments. The goal is to gather information to better understand the problems under evalua- tion under both the Company's point of view and the ergonomists.

Appraisal with workers' direct participation is carried out to obtain the workers' point of view. Workers are invited to participate in open interviews (of a qualitative nature) and to answer questionnaires (of a quantitative nature) as set out in the Macroergonomic Design (MD) tool [11,21]. The interviews, which are semi-structured, come from a generic question: tell me about your work?

All 16 workers from the sector were interviewed by 2 specialists in groups of 3 to 4 people, according to their availability in the day. The interviews lasted 20-30 minutes. The most commented items were related to the work organization, the high level of physical effort demanded to perform the tasks and the Company's politics.

From the interviews, a 70 questions questionnaire was drawn up to measure how the employees evaluate their work considering the ergonomic demand items (EDIs) verbalized in the interviews and also the ones identified by the researchers. The EDIs are organized in six constructs: 5 questions about the satisfaction with the physical environment, 6 questions about the satisfaction with the workstation, 17 questions about the satisfaction with the work organization, 5 questions about the EDIs that impact the work organization, 21 questions about the work content, 7 questions about the satisfaction with the Company, 3 questions related to safety/risk, and 6 questions about the perception of pain. Measurement of the answers is made using a $15 \mathrm{~cm}$ continuous assessment scale, suggested by [16] with two anchors at the ends (dissatisfied or not at all; satisfied or very much), and somewhere along it, the worker should mark his/her perception about the EDI. As the scale is $15 \mathrm{~cm}$ long, the intensity of each response may vary between 0 and 15 . The weight of each EDI is generated by the arithmetic mean of the results from the respondents.

Fourteen workers responded the questionnaires. Before the application, the researchers explained the objectives of the research as well as the volunteer and confidential character of workers' participation in the study. The researchers read/explained the questions to the workers with reading difficulties. All participants signed a consent form.

\subsection{Evaluation of Postural Risk}

Postural risk was evaluated with the Ovako Working Posture Analysis System - OWAS [26]. The work was videotaped, and analyzed with the software Wi- 
nOWAS $\AA$. For the traditional packaging model, 100 images were evaluated in 10 seconds interval. For the mechanized model, 300 images were evaluated: 100 in the beginning of the line, 100 in the middle and 100 in the end.

\subsection{Statistical analysis}

The questionnaires showed consistency by Cronbach's alpha (alpha $=0.8759,>0.55)[22]$ but data did not show normality. Therefore they were analyzed by descriptive and the results of the IDEs of each construct from the two different models were compared with non-parametric statistics by the Kruskal-Wallis test using the SPSS ${ }^{\circledR}$ software.

\section{Results}

\subsection{Description of the work}

\subsubsection{The traditional model}

In the traditional model, each worker is responsible for the whole luminary packing. The task involves the following activities: i) to get the luminary from the assembly sector nearby; ii) to put the luminary it the box and close it; iii) to put the box on a pallet for later conference e delivery. The task is done every 15 seconds, in average.

\subsubsection{The mechanized model}

In the mechanized model, the task was decomposed in an activity per worker, i.e., one worker just gets the luminary from the stand, a second one just moves the luminary to the new packing machine, and a third one just gets the packed luminary from the machine to put it on the pallet, each task with a mean cycle time of 5 seconds. Therefore, the work was designed as a line with three workstations: i) Start of the line: the worker gets the luminary from the assembly sector nearby; puts the luminary in the top of a pre-folded box. Basically, the worker adopts a static, standing up position with trunk rotation; ii) Middle of the line: a second worker pushes the box towards the machine that makes the packing, the sealing and even moves the package to the end of the line; iii) End of the line: the third worker gets the package, verifies the sealing and puts it on the pallet for later conference and delivery.

Both traditional and mechanized models are characterized as highly repetitive, since the task cycle is less than 30 seconds [3], the task being done more than $50 \%$ of the journey [27], The use of same musculoskeletal groups for performing a task imposes both biomechanical and mental constraints since repetitive work is monotonous, often resulting in high rates of WMSD, illness, absenteeism and turnover.

This study did not evaluate the medical and professional outcomes of the work at the Company's packaging sector but found that improvements are needed to enhance the workers' satisfaction with the work and minimize pain/discomfort and WMSD risk, as described in the following sections.

\subsection{Results from the questionnaires}

Figure 1 presents the general results of the workers' perception of their work, per construct, independent of the type of model. Satisfaction with the environment is the only construct with a satisfaction mean below average.

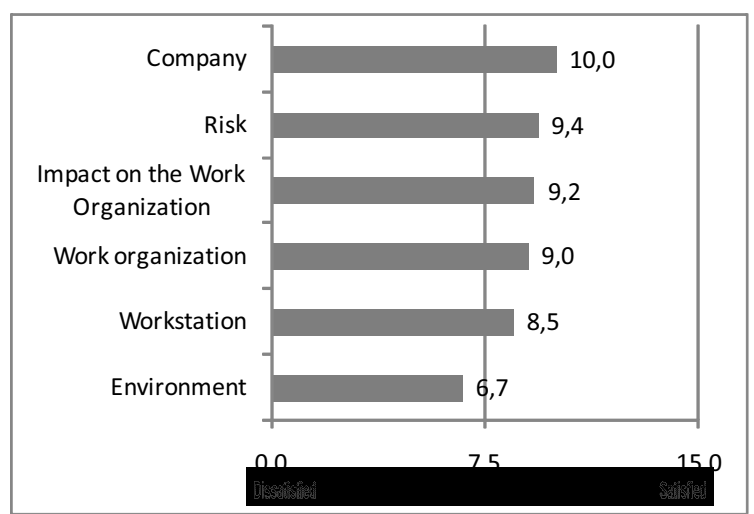

Fig. 1. Mean values for 6 constructs independent of the work system. Scale varies from 0 (dissatisfied or not at all) to 15 (satisfied or very much).

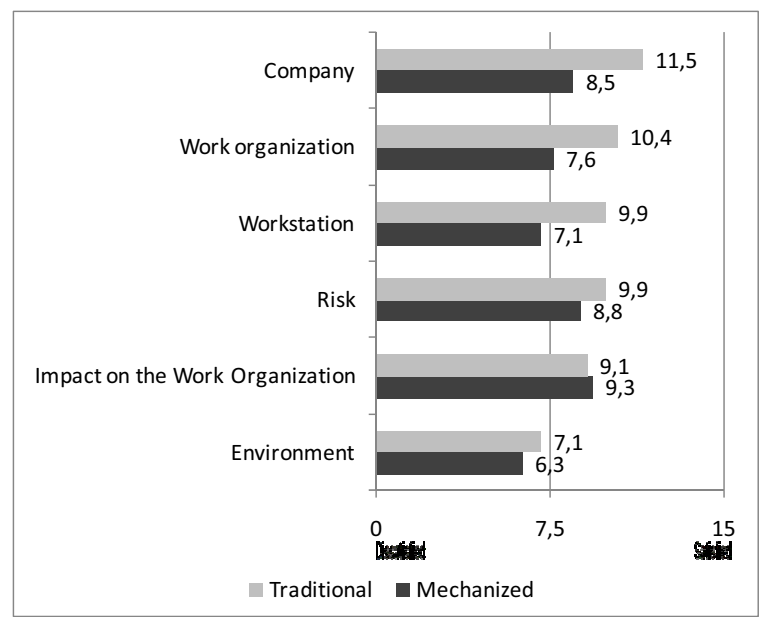

Fig. 2. Mean values for 6 constructs according to the work system. Scale varies from 0 (dissatisfied or not at all) to 15 (satisfied or very much). 
When the results are evaluated according to the type of work design, there are differences that should be discussed. Figure 2 presents the comparative results between the two models, making it clear that the type of model impacts the results. The level of satisfaction of the workers operating in the mechanized model is consistently lower than the ones acting in the traditional model, as can be depicted from the following analysis.

The IDEs temperature, air quality and ventilation are the IDEs that generates more dissatisfaction among the workers. The reason is the fact that the sector is installed in a warehouse, with no exhaustion, proper ventilation or acclimatization. Noise is another IDE that generates dissatisfaction, pointing out that urgent measures should be taken to improve the environment. The sources of noise are the machines from the nearby sectors that lead to a noise level of $80 \mathrm{~dB}(\mathrm{~A})$. Although this level is below the limit of $85 \mathrm{~dB}(\mathrm{~A})$ for 8 hours continuous work according to Brazilian norm NR15 [13], this level is annoying, disturb the work and even can lead to hearing loss therefore workers use Personal Protection Equipment (PPE). Norms NR9 [1] and NHO-01 [12] establish $80 \mathrm{~dB}(\mathrm{~A})$ as the limit for a company start a prevention program to avoid hearing impairment.

The Man Whitney U test test showed statistically significant differences between the levels of satisfaction of the workers in the mechanized and traditional model in relation to the EDIs temperature $(p=0.05)$ and illuminance $(\mathrm{p}=0.009)$ in the construct Environment (Figure 3) the mean levels of satisfaction being lower for the workers of the mechanized model.

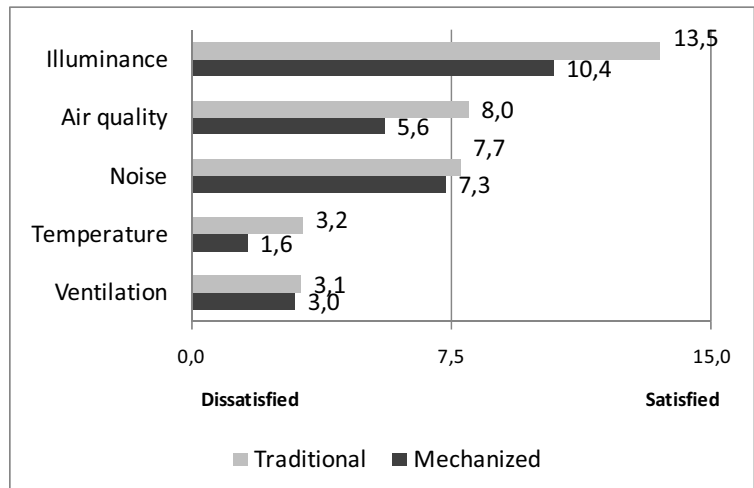

Fig. 3. Mean values for the EDIs of the Environment construct according to the two work systems. Scale varies from 0 (dissatisfied) to 15 (satisfied)

Figure 4 shows that in the Workstation construct, all IDEs but the quality of the equipments are above the mean level of satisfaction for the workers of the traditional model. Although the adopted posture to perform the work seems to be worse for the workers of the mechanized model, statistically, the only difference between the opinions of the workers of the traditional and mechanized models are in relation to the workspace $(\mathrm{p}=0.03)$ and the uniform $(\mathrm{p}=0.05)$, which are considered worse by the workers of the mechanized model. It is worth noting that the uniform is the dame for all workers.

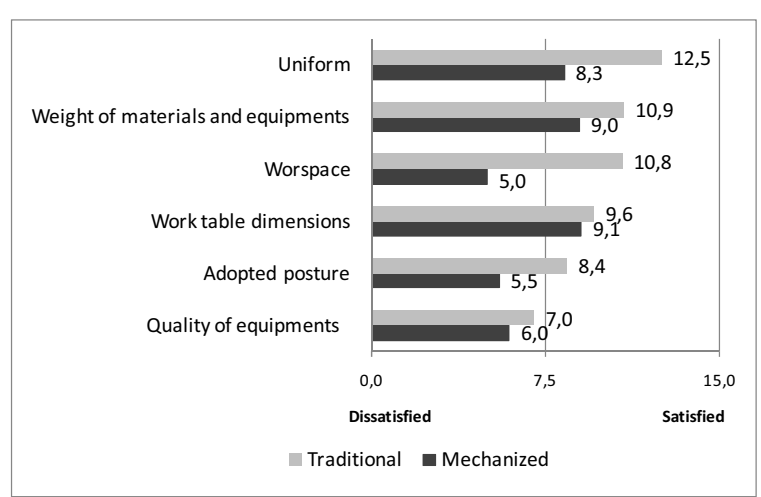

Fig. 4 Mean values for the EDIs of the Workstation construct according to the two work systems. Scale varies from 0 (dissatisfied) to 15 (satisfied).

Among the most important results of the Work Organization construct (Figure 5) are the dissatisfaction with the form of evaluation demand for production $(p=0.017)$ and quantity of pauses in the mechanized model $(\mathrm{p}=0.05)$, which are not problems for the workers of the traditional model. This can be explained by the different roles the workers play in the two different models. While in the traditional system the worker performs all the activities for packing the luminaries in his one pace, the worker in the mechanized model performs three times less activities at the pace of the machine. Work segmentation and the need to follow the pace of the machine impacted on work flexibility since there is no room for pauses and one worker depends on the other. This new condition impacted negatively on the satisfaction with the number of pauses $(p=0.05)$, on the number of workers involved in the new system $(\mathrm{p}=0.004)$, on the way that work is evaluated and production is requested $(\mathrm{p}=0.017)$, on the relationship with the supervisors $(p=0.009)$ and consequently with the satisfaction with the supervisors' behavior $(\mathrm{p}=0.009)$. However, it did not impact on the relationship with the colleagues. Despite the problems, it is important to note that they like the job rotation. The workers acting in the traditional model seems less satisfied (but there was not statistical difference) with the job rotation what was 
expected since they do not have it. The quantity of boxes available for the work is a concern for the two groups.

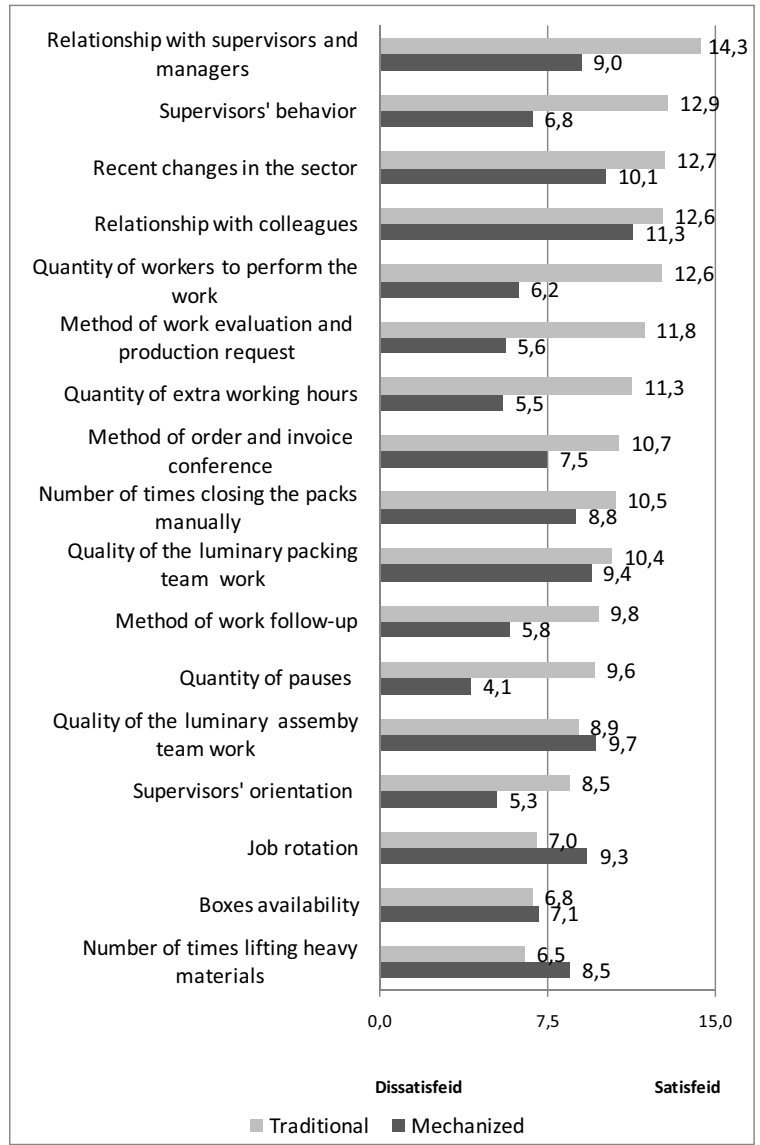

Fig. 5 Mean values for the EDIs of the Work Organization construct according to the two work systems. Scale varies from 0 (dissatisfied) to 15 (satisfied).

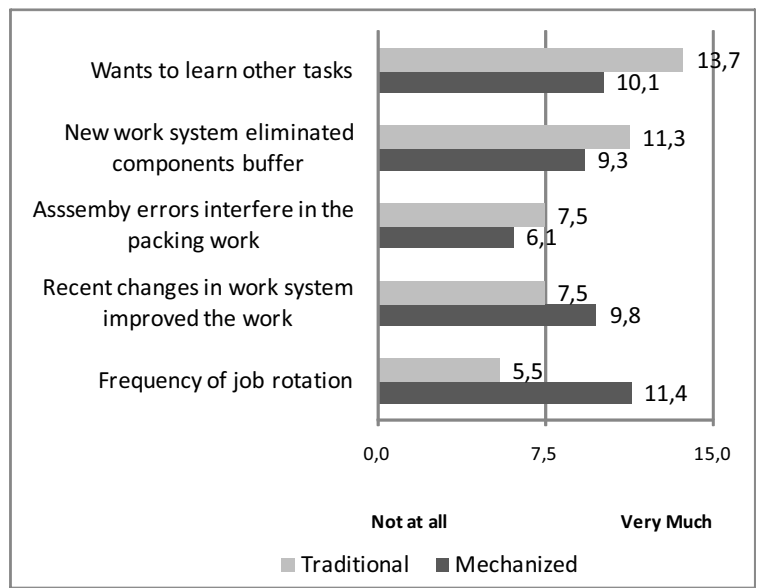

Fig. 6 Mean values for the EDIs that impact on the Work Organization, according to the two work systems. Scale varies from 0 (not at all) to 15 (very much).
Figure 6 shows the impact of some IDEs on the work performed. Before the ergonomic analysis, the Company tried to improve the work system by adding the tasks carried out at the end of the assembly line with the packing. They were successful, because the workers found that the change improved the work. Although the majority of the workers do not work with the new machine, they work in the same sector and they were also questioned about the impact of mechanization. They understand that the new system reduced the luminaries' buffer and that the error that might occur in the assembly sector do not have too much impact on their work. However, the buffer was not completely eliminated and when the luminaries are easily assembled the buffer increases. In this case, mainly the workers of the mechanized model cannot adjust their work rhythm with the machine's pace.

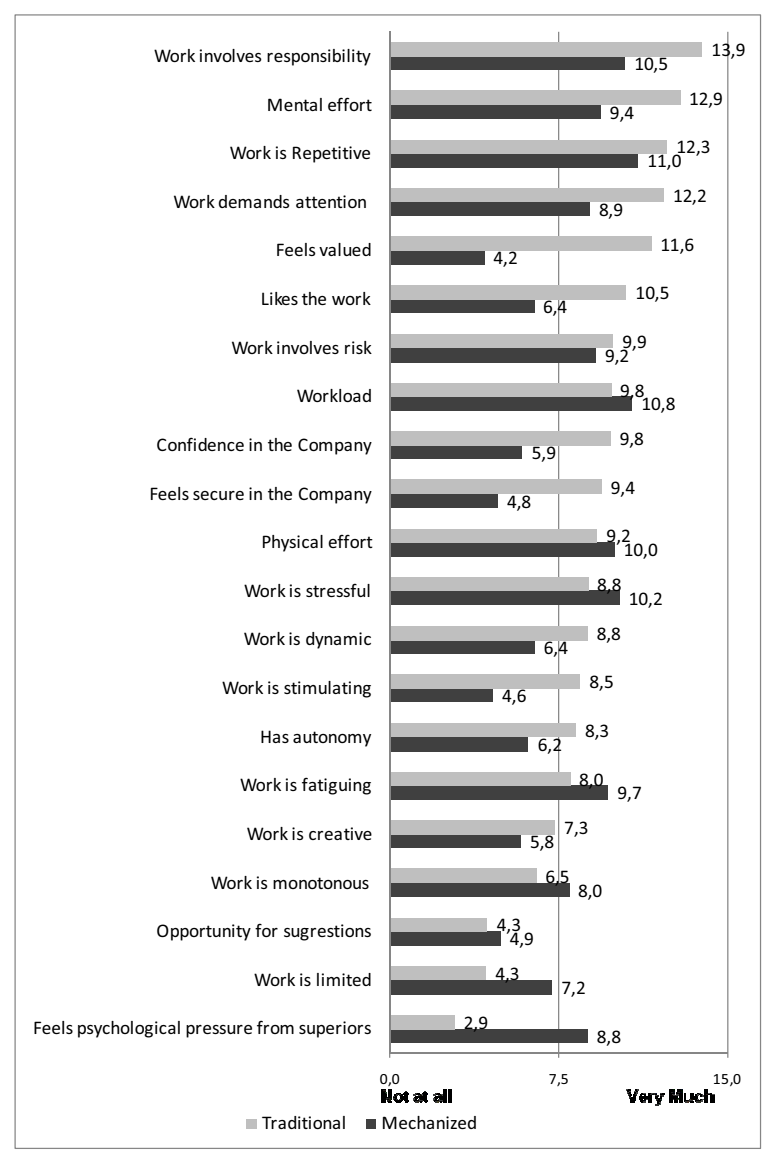

Fig. 7 Mean values for the EDIs of the Work Content construct according to the two work systems. Scale varies from 0 (not at all) to 15 (very much).

The most important finding is that mainly the workers of the traditional model want to learn more to perform other tasks $(p=0.05)$, what opens an op- 
portunity for task enrichment. This result is consistent with the awareness that the frequency of job rotation improves their work, therefore a more frequent job rotation should be implemented for all workers.

The Work Content (Figure 7) is probably the most import construct since it reveals how the workers perceive their work. The workers understand that their work is monotonous, repetitive, stressful because the workload is high, demanding both physical and mental effort and attention, being fatiguing. However it is dynamic, stimulating and they have autonomy to do the work as they want to therefore, they like the work. However, the workers in the mechanized feel more pressure from their supervisors $(p=0.05)$, feel less valued by the Company $(p=0.017)$ therefore do not feel as responsible for the work as the traditional workers do $(\mathrm{p}=0.017)$.

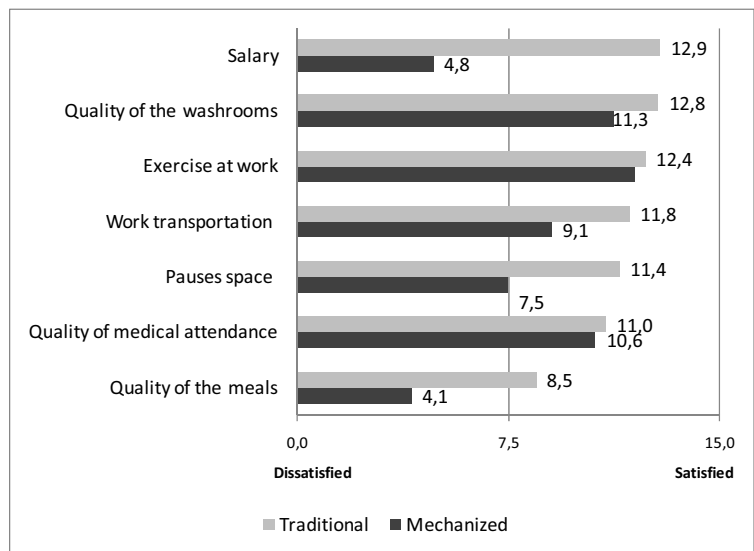

Fig. 8 Mean values for the EDIs of the Company construct according to the two work systems. Scale varies from 0 (dissatisfied) to 15 (satisfied).

Figure 8 presents the results of the Company construct. Both groups are satisfied with all IDEs but salary (there was not significant difference for the IDE quality of meal). The workers of the mechanized model are less satisfied with their salary in comparison with the workers of the traditional model $(\mathrm{p}=$ 0.03 ), although the workers have the same wage.

Figure 9 presents the results of the questions about the safety issues. Both groups do not feel the Safety team is good enough for a work that is not as safe as should be. The Personal Protection Equipment (PPE) are above the mean level of satisfaction.

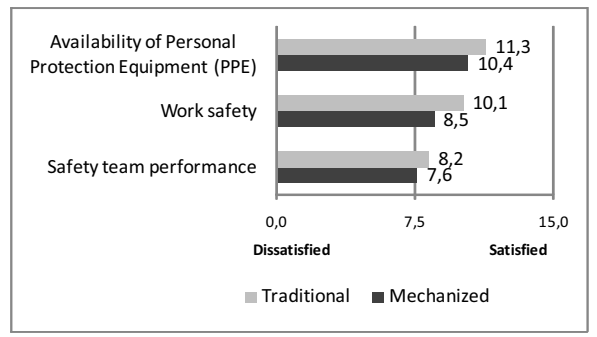

Fig. 9 Mean values for the EDIs of the Safety/Risk construct according to the two work systems. Scale varies from 0 (dissatisfied) to 15 (satisfied).

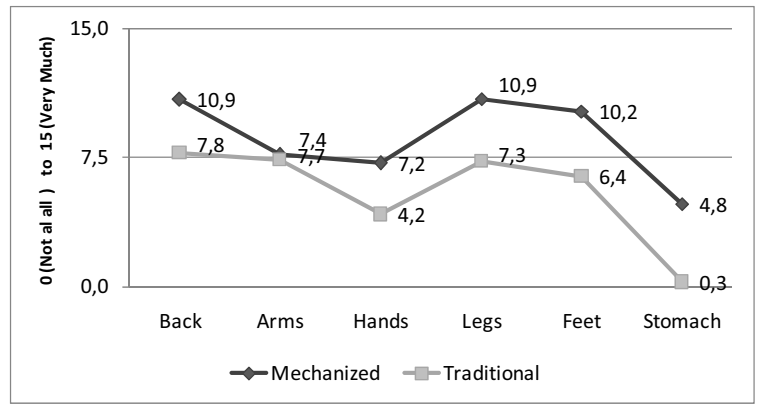

Fig. 10 Mean values for the intensity of discomfort/pain according to the two work systems. Scale varies from 0 (not at all) to 15 (very much).

Pain and discomfort reflects the load imposed on the workers. As per Figure 10, the workers feel pain in the lower, middle and upper part of the back, neck, legs, feet, arms and hands. Pain seems to be higher for the workers in the mechanized model what should be expected since the task is more repetitive therefore overloading some parts of the body. Although job rotation was implemented in the mechanized model, it did not have any positive effect on the overload since it happens at each day, i.e., workers change the position in the line everyday but keep doing the same task all journey what does not allow for musculoskeletal recuperation. However, there was statistical difference only for pain in the head $(\mathrm{p}=0.004)$ and stomach $(p=0.004)$, which are higher for the workers in the mechanized model.

\subsection{Results from the OWAS protocol}

The results from the OWAS protocol show that the mechanized model imposes postural risk due to the bent and twisted postures adopted to cope with the tasks. $72 \%$ of the time the back was bent and in only $28 \%$ of the time it was in a neutral position. The workers were in a standing up position with the legs straight in $59 \%$ and inflected in $14 \%$ of the observations, while they were moving in $16 \%$ of the time. 
The back was bent and the arms were below the line of the shoulders in most observations.

In the mechanized model, the workers in the start of the line kept the back twisted in $41 \%$ of the observations; it was bent in $18 \%$ of the observations; bent and twisted in $9 \%$ of the time; and straight in $32 \%$. The legs were straight in a static posture in all observations. The arms were below the line of the shoulders all times. The static posture repeats itself every 5 seconds, which is the task cycle time. The results are consistent with the feeling of discomfort/pain in the back, legs and feet.

In the middle of the line, the workers have the back bent in $67 \%$ of the observations, and twisted in $33 \%$ of the time. The legs were straight in all observations, the worker standing up all journey, repeating the same task every 5 seconds. The static position reflected on the discomfort/pain in the back, legs and feet.

At the end of the line, in $63 \%$ of the observations the back was bent, and straight in $37 \%$ of the time. Workers adopted a standing up static position, with the legs straight in $21 \%$ of the observations, and inflected in $63 \%$ of the time. They were in movement $16 \%$ of the time. In $16 \%$ of the observations the workers were handling weights between 10.1 and $19.9 \mathrm{~kg}$.

\section{Discussion}

The results for the mechanized model are in agreement with the study by [17] in the packing sector of a Dutch tobacco manufacturer where the tobacco is packed mechanically into small bags and subsequently into cartons that are then packed by hand into a box, closed and stacked on a pallet. The problems found were high noise levels, isolated workstations, which result in low interactions among workers, lack of buffer space, which makes it impossible for the workers to leave the workstation. The tasks were machine paced with a short cycle time, allowing the packers no possibility to choose their own pace and work sequence. Women, specially, experienced strenuous physical exertion and low job satisfaction. The workstation was redesigned and a new work organization was proposed with one machine-operator working at two machines, and shifting some of the manual tasks between two packers.

In the present study, the mechanized model showed to be worse than the traditional one in some EDIs of the Environment construct (temperature and illuminance, although they are the same as in the traditional workstations), Workstation (wokspace and uniform) and Work Organization (relationship with supervisors and managers, quantity of workers to perform the work, method of work evaluation and production request, supervisors' behavior, quantity of pauses). The workers of the mechanized model feel less responsible for their work, feel more psychological pressure from supervisors and feel less valued by the Company. They are unsatisfied with the salary, although it is the same perceived by the colleagues working in the traditional model. All workers feel pain in the back, arms, legs and feet due to the standing up static position adopted to perform the repetitive tasks and manually handle the loads.

Job rotation was well evaluated, therefore it should be introduced in the traditional model, but the frequency should be increased because the current frequency (rotation every day) is not enough. A reasonable solution is to leave the workers rotate before they feel fatigue. [19] found individual preferences for time rotation frequency in a shoe manufacturing company but in general the workers rotate at least four times in a day. Considering the work (both in the traditional and mechanized models) is not as large/rich as it should be, job rotation should include other activities that are not being performed so far. As the workers are willing to learn other activities, the proposals for improving the work organization are to expand the packers' task by allowing them to also work in the luminary assembly sector. The workers made it clear that they would like to perform more tasks since the work is very repetitive. Although training will be required, adding the two sectors will enlarge/enrich the work done in the two sectors, making job rotation more valuable.

Although the traditional model was in general better evaluated than the mechanized one, it cannot be considered adequate. The physical environment needs, at least, better temperature control and ventilation, by opening windows, using ventilators etc. Isolating the sources of noise of the machines as well as their maintenance enhancement should reduce noise.

The tables and layout of the mechanized workstation needs to be re-designed to eliminate the adoption of awkward postures of back, arms, legs and knees. The introduction of carts would minimize the need for material handling and the introduction of seats are necessary for posture alternation. In the traditional workstations, the cutters should be replaced by better ones, to reduce strain on the hands. The table's dimensions should be adjusted in order to avoid awkward postures. Some table's surfaces offer too much resistance to the packs making it difficult to push them therefore their finishing should be improved. 
Carts should also be introduced to minimize material handling.

There is a need for introducing a special place for the breaks, with seats, water fountain and coffee, so the workers can have pauses with no noise and other stressors from the production sector. Pauses are mandatory by Brazilian Ergonomics norm NR17 [6], therefore workers and supervisors should be informed about the importance of making breaks as well as job rotation, and the production goals should be adjusted considering the necessary pauses. The exercise program was well evaluated by the workers and should be kept.

\section{Conclusions}

This article evaluated two luminary packing systems carried out in the same sector. The mechanized system involves a three workers team while the others continue working under the traditional model, with no packing machine. Results showed that against the managerial staff expectations, the work is worse in the mechanized model. Postural risk is higher than in the traditional model, since the work was segmented in three, the three workers in the line having a very short cycle task. Therefore, the workers feel more pain and are less satisfied with their jobs, even with the environment, uniform and salary that are the same for the two groups. Although the traditional model needs improvements, the introductions of a packing machine worsen the work both physically and mentally. The proposition is not to buy more packing machines and use the money to improve the physical environment, the workstations, introduce a special place for breaks and train the workers of the packing sector to act in the assembly and vice-versa, in order to enlarge/enrich the work in both sectors.

\section{References}

[1] A. Carlsson, Hand injuries in Sweden in 1980, Journal of Occupational Accidents, 6 (1984), 155-165.

[2] B. Falck and P. Aarnio, Left-sided carpal tunnel syndrome in butchers, Scandinavian Journal of Work and Environmental Health, 9 (1983), 291-297.

[3] B.A. Silverstein, L.J. Fine and T.J. Armstrong, Hand wrist cumulative trauma disorders in industry. Occup. Environ. Med., 43 (1986), 779-784.

[4] Brasil, Ministério do Trabalho e Emprego (MTE), Norma Regulamentadora NR15. Portaria 3.214/78 de 8 de junho de 1978

[5] Brasil, Ministério do Trabalho e Emprego (MTE), Norma Regulamentadora NR9. Portaria $3.214 / 78$ de 8 de junho de 1978 .
[6] Brasil, Ministério do Trabalho e Emprego (MTE) 1978c. Norma Regulamentadora NR17. Portaria 3.214/78 de 8 de junho de 1978.

[7] C. Carrasco, N. Coleman, S. Healey and M. Lusted, Packing products for customers: An ergonomics evaluation of three supermarket checkouts. Applied Ergonomics, 26 (2): 1995 , 101-108.

[8] C. Dejours, Travail: usure mentale. Paris: Le Centurion, 1980.

[9] E. Delgado, T. Bustos and A M. Genaidy, Active microbreaks effects on musculoskeletal discomfort perceived in meatpacking plants' in Karwowski, W and Yates, J W (eds) Taylor \& Francis, London (1991) pp 137-142.

[10]E. Grandjean, Fitting the task to the man: an ergonomic approach. London: Taylor \& Francis, 1981.

[11]F.S. Fogliatto and L.B. de M. Guimarães, Design macroergonômico: uma proposta metodológica para o projeto de produto, Produto \& Produção, 3 (1999), 1-15 (in Portuguese).

[12]Fundacentro- MTE 2001 NHO 01, Norma de Higiene Ocupacional: Procedimento Técnico para Avaliação Ocupacional da Exposição ao Ruído, 2001.

[13]G. Friedman, Le travail en miettes: spécialisation et loisirs. Paris: Gallimard, 1967.

[14]H. Braverman, Labor and monopoly capital: the degradation of work in the twentieth century. New York: Monthly Review Press, 1998.

[15]H.D. Enslow, Ergonomics considerations in designing a carton packing station: In: Ergonomics in Industry. Proc 2nd Conf New Zealand Ergonomics Soc, Wellington, 11-12 August 1988, pp 235-245.

[16]H. Stone, J. Sidel, S. Oliver, A. Woolsey and R.C. Singleton. Sensory evaluation by quantitative descriptive analysis. Food Technology, 28 (1), 1974, 24-34.

[17]J. C. M. Mossink, Case history: design of a packaging workstation. Ergonomics 33 (4): 1990, 399-406.

[18] J.S. Moore and A., Garg Participatory ergonomics in a red meat packing plant, Part I: Evidence of long-term effectiveness. Am. Ind. Hyg. Assoc. J 58/2: 1997, 127-131.

[19] J.S. Renner, Proposal of a new work design for the shoe manufacturing under he sociotechnical approach. Thesis (Dr.) Federal University of Rio Grande do Sul. 2007.

[20]L.B. de M. Guimarães, Abordagem ergonômica: o método Macro. In: L.B. de M. Guimarães, coord. Ergonomia de Processo. Porto Alegre: FEENG, Vol 1, Chapter 1 (1999), 116.

[21]L. B. de M. Guimarães and F. S. Fogliatto, Macroergonomic design: a new methodology for ergonomic product design. In: 14th triennial meeting of the international ergonomics association. San Diego: International Ergonomics Association, 2000.

[22]L. J. Cronbach, Coefficient alpha and the internal structure of tests. Revista Psychometrika, 16 (1951), 297-334.

[23] M. L. Finkel, The effects of repeated mechanical trauma in the meat industry, American Journal of Industrial Medicine, 8 (1985), 375-379.

[24]M. Magnusson and R. Ortegren, Investigation of optimal height and surface angle in meatcutting, Applied Ergonomics, 18 (1987), 146-152.

[25]M. Magnusson, Ortengren, R., G. B. J., Andersson, I., Petersen and B., Sabel, An ergonomic study of work methods and physical disorders among professional butchers, Applied Ergonomics, 18 (1987), 43-50.

[26]O. Karhu, P., Kansi, and I., Kuorinka, Correcting working postures in industry: a practical method for analysis. Applied Ergonomics, 8(4): 1977, 199-201. 
[27]P. Roto and P. Kivi, Prevalence of epicondylitis and tenosynovitis among meatcutters, Scandinavian Journal of Work and Environmental Health, 10 (1984), 203-205.

[28]E. W. Streib and S. F. Sun, Distal ulnar neuropathy in meat packers. An occupational disease, Journal of Occupational Medicine, 26 (1984), 842-843.
[29]E.Yiikari.Juntura, Neck and upper limb disorders among slaughterhouse workers. An epidemiologic and clinical study, Scandinavian Journal of Work and Environmental Health, 9 (1983), 283-290. 